\title{
The Impact of 3D Printing Technology on Supply Chain
}

\author{
Lukáš Kubáč ${ }^{* 1}$, and Oldřich Kodym² \\ ${ }^{1}$ Technical University of Ostrava, 17. listopadu 2172/15, 70800 Ostrava, Czech Republic \\ ${ }^{2}$ College of Logistics, Přerov, Palackého 1381/25, 75002 Přerov, Czech Republic
}

\begin{abstract}
D printing technology has emerged as one of the most disruptive innovations to impact the logistics industry and the global supply chain. Some claim that the technology merely enhances some aspects of production process, while others argue that technology will revolutionize and replace existing manufacturing technologies. Whether revolutionary or evolutionary, $3 \mathrm{D}$ printing technology is recognized as an important trend that will significantly impact supply chains. The objective of this article is to explore basic issues related to $3 \mathrm{D}$ printing technology and possibilities for altering manufacturing and supply chain.
\end{abstract}

\section{Introduction}

Since the Industrial Revolution, manufacturing has been synonymous with factories, machine tools, production lines and economies of scale. So it is startling to think about manufacturing without tooling, assembly lines or supply chains. However, that is what is emerging as the future of $3 \mathrm{D}$ printing services takes hold. Today you can make parts, appliances and tools in a wide variety of materials right from your home or workplace. Using a computer, simply create, modify or download a digital 3D model of an object. 3D printers are being used to economically create custom, improved, as well as design of parts that could not be manufactured before, and right there where they will be used. A single printer can produce a vast range of products, sometimes already assembled.

\subsection{What is 3D printing}

3D printing, also known as additive manufacturing - $\mathrm{AM}$ (the terms 3D printing and additive manufacturing have become interchangeable), is an additive technology used for making three dimensional solid objects up in layers from a digital file without the need for a mould or cutting tool. 3D printing uses a computer aided design (CAD) to translate the design into a three-dimensional object. The design is then sliced into several twodimensional plans, which instruct the 3D printer where to deposit the layers of material. Additive process, of depositing successive thin layers of material upon each other, producing a final three dimensional product [1]. A wide variety of materials can be utilized

* Corresponding author: lukas.kubac@,vsb.cz 
- plastics, glass, metal, polymers, wax, sand and glue mixes, nylon, ceramic, edible material, and even human tissue.

Three basic ingredients are essential for creation of a 3D object - a digital model, feed material and a $3 \mathrm{D}$ printer (fig. 1).

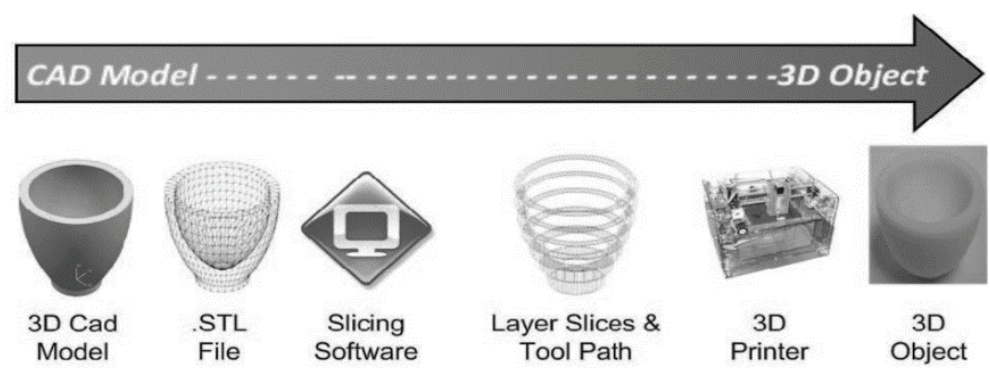

Fig. 1. Generalized additive manufacturing process. Source: [2]

\subsection{Basic advantages and disadvantages of 3D printing}

\section{Advantages}

- Less setup costs and less tooling costs

- Lower production costs

- Lower development time and costs (increase the pace of design to product)

- Eco friendly: less influence on $\mathrm{CO} 2$

- Lower cost price for small volumes and complex shaped parts

- Shorter delivery time

- Complex products relatively easy to print

- Flexibility (printing on-demand, customisation)

\section{Disadvantages}

- Lower production speed

- Higher investment costs

- Unclear responsibilities regarding intellectual property

- Liability - warranties, certification

- Process variability/ quality

- Not efficient for large series

- Limited choice of material (sometimes)

- Limited dimensions of product

- Complexity of the Supply Chain (3D printing is added to the Supply Chain)

Logistics service providers will only be allowed to store and print out the data models if the manufacturers trust them and are prepared to give them the 3D data models. What's certain is that in future, the "value" of a product will reside in a digital file. Manufacturers will try to protect their intellectual property by inserting copy protections and assigning licensing rights [3].

There are still some limitations to be compensated, such as durability and other material related characteristics of the printed components, printing time, and the price of raw materials and commercially available printing equipment. However, it seems that technology evolution is beating the limitations one by one.

$3 \mathrm{D}$ printing is not yet conducive to mass production due its typically higher cost per unit and slower production time per unit. If the new technology is to completely transform 
global industry, 3D Printing must be able to mass produce goods in the same volumes as traditional manufacturing techniques.

\section{Challenges}

Like any disruptive new opportunity, on-demand AM manufacturing networks have challenges that must be addressed [4]. Challenges exist in three major areas:

\section{Technology and Engineering}

- Different design principles and stress data for each different AM technology

- Intensive investment in engineering training and process maturity is needed

- Slight changes in material properties can make one-to-one replacements difficult (sometimes)

- Extensive post-processing (heat-treat, machining...) are presently at lower levels of automation

\section{Data Management}

- Future geographical and/or organizational separation of the design and production organizations requires a secure transfer of approved design data (i.e. build file, material specifications)

- Design may only be printed on a qualified printer and must be authorized to print the part

- Design and build data must be traceable against source requirements

\section{Business Impacts}

- Local printing in comparison to centralized printing offers significant availability/lead time advantages for spare parts supply

- Supporting platforms over decades of use

- Intellectual property protection for design and printing data

- Opens the door to new business models and modes of operation

- Designs may be licensed for print by authorized end users

- Subscription models for parts catalogues

\section{Impact of 3D printing on the Supply Chain}

The impact of AM technologies on the global setup of supply chains can be very disruptive. The technology has the potential to eliminate the need for both high volume production facilities and low-level assembly workers, thereby drastically reducing supply chain cost $[5]$.

In terms of impact on inventory and logistics, we can print on demand. Meaning we don't have to have the finished product stacked on shelves or stacked in warehouses anymore. Whenever we need a product, we just make it. And that collapses the supply chain down to its simplest parts, adding new efficiencies to the system. Those efficiencies run the entire supply chain, from the cost of distribution to assembly and carry, all the way to the component itself, all the while reducing scrap, maximizing customization and improving assembly cycle times. 


\subsection{Traditional supply chain vs AM model}

The supply chain traditional model is founded on traditional constraints of the industry, efficiencies of mass production, the need for low cost, high volume assembly workers, and so on. But 3D printing bypasses those constraints. 3D printing finds its value in the printing of low volume, customer specific items, items that are capable of much greater complexity than is possible through traditional means. This at once eliminates the need for both high volume production facilities and low level assembly workers, thereby cutting out at least half of the supply chain in a single blow. From that point of view, it is no longer financially efficient to send products across the globe when manufacturing can be done almost anywhere at the same cost or lower. The raw materials today are digital files and the machines that make them are wired and connected, faster and more efficient than ever. And that demands a new model of supply chain [6].

With support local sourcing, the 3D printing technology has the potential to tear established global supply chain structures apart and reassembles it as a new, local system. Furthermore, the technology creates a close relationship between design, manufacturing and marketing. The technology could transform the global supply chain to a globally connected, but totally local supply chain [7].

Let's take a look at the differences in today's more traditional supply chain versus what it could look like in the future with more 3D printing and the supply chain:

Traditional Supply Chain

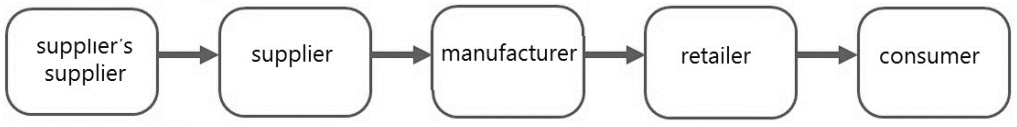

Additive Manufacturing model

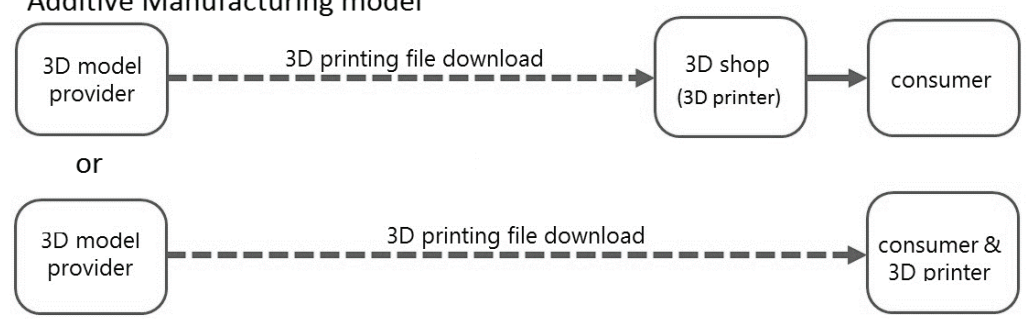

Fig. 2. Supply chain - Traditional and AM model. Source: [8]

\section{Traditional Supply Chain}

- Products are mass produced (e,g. in China)

- Manufactured goods are 'pushed out' and distributed through warehouse network to customers

- Long lead time

- High transport costs

- Large carbon footprint

\section{Additive Manufacturing model}

- Customised production

- 'Pulled' by end customer demand

- Locally printed and distributed

- Short lead time

- Low transport costs

- Low carbon footprint 
Generalized processes in traditional supply chain and Additive Manufacturing model see Fig. 2.

\subsection{Advantages of AM model}

\section{Cost Savings}

- Eliminate the need for large bulk inventory

- Eliminate the need for high volume production facilities

- Reduce transportation cost

- Eliminate penalty for redesign

- Reduce the size of an economical lot

- More economical and effective packaging solutions

- Vetting out designs: offer customized designs at lower cost

- Reduce labor inputs: eliminate low level assembly workers

- Reduce required tooling and machining centers

- Economical mass customization

\section{Speed Responsiveness}

- Eliminate the time lag between design and product

- Shorter lead time

- Enabling on-demand manufacturing

- Improving process flexibility

- Supply chain disintermediation

\section{Quality Improvement}

- Reduce production waste

- Improve quality

- Incorporate customer feedback

- More optimum products across many industries

- Eliminate excess parts that cause drag and add weight

- Management of demand uncertainty

\section{Environmental Impact}

- Less negative impact on environment

- Reduce carbon footprint

- Reduce the waste that accrue in traditional manufacturing

With 3D printing, manufacturing will become more agile and better able to react to customer demands. This means there will be less work-in-progress and finished product in transport and in stock and less obsolescence of existing stock. Although the cost per unit may be higher, with reduced storage and less outdated product, the overall supply chain system costs may be lower than that of traditional manufacturing supply chains. Products can be made closer to the consumer $[9,10]$. 3D printing supports a build-to-order, mass customization environment, and in some cases it will allow for product differentiation to be postponed in the supply chain process. There will be a dramatic increase in information transmission. The feedstock, often very versatile and useful for several products, becomes the inventory. This process is ideal for small batches and uncertain demand [7].

Opportunities for 3D printing are not entirely captured by the reduction of manufacturing costs, even though it is likely for low-volume parts that the manufacturing costs can be reduced because of lower setup and tooling costs. AM offers opportunities for new marketing strategies and distribution channels. Instead of manufacturers producing products based on forecasted demands, 3D printing allows for manufacturing based on real- 
time demand. This results in shorter lead times from order to delivery. The supply chain will be much more flexible in order to accommodate surges in product demand [11].

Global networks of 3D printing installations will give enterprises the ability to respond rapidly to shifts in market demand and to introduce new products quickly and inexpensively. More versatile design processes could unleash a new wave of product innovation. In the longer term, the technology has the potential to redefine traditional manufacturing methods. The concept of making products in large, complex plants could become outmoded as companies adopt the more flexible additive manufacturing model.

\subsection{Implications for the logistics industry}

The implications of this new manufacturing technology for the logistics industry could be massive:

- Potentially a proportion of goods which were previously produced in China or other Asia markets could be 'near-sourced' to North America and Europe. This would reduce shipping and air cargo volumes.

- Customisation of products would mean that inventory levels fall, as goods are made to order. This would have the effect of reducing warehousing requirements.

- Downstream logistics would also be affected. Build-to-order production strategies could fundamentally impact the manufacturer-wholesaler-retailer relationship. In the future the shopping experience could also be vastly different. In some sectors, retailers will either cease to exist or become 'shop windows' for manufacturers, keeping no stock of their own. Orders are fulfilled directly by the manufacturer, and delivered to the home of the consumer [12].

- A major new sector of the logistics industry would emerge dealing with the storage and movement of the raw materials which 'feed' the 3D Printers. As 3D Printers become more affordable to the general public, the home delivery market of these materials would increase.

- The Service Parts Logistics sector would be one of the first to be affected. At present billions are spent on holding stock. If you can download a design from the online library, print $3 \mathrm{D}$ and then enter it in a very short time window, then global and national warehouses as well as front warehouses will not be needed [9].

\subsection{Applications in Industries Supply Chain}

The breadth and impact of AM continues to expand as the technology gains acceptance and functionality, making it a feasible means of production in a variety of industries. In the past few years, many companies have adopted AM and are beginning to rip the real benefits from the technology. Healthcare, automotive and aerospace industries are among the sectors with the greatest transformative potential. AM technology has been pushed beyond the realm of prototyping and has become an effective means of advancing the way parts and tools are produced in the Aerospace industry. AM makes it possible to have objects printed in remote locations, as delivery of goods is no longer a restriction. This benefit of AM makes it possible for the use for technology in Space. NASA has been testing AM in zero gravity in hopes of establishing on-demand manufacturing for astronauts. This would allow component parts for maintenance and repair of the international space station to be manufactured in Space. This would decrease the need for shuttle to make trips to the international space station to deliver parts, thus greatly reducing the lead-time on replacement parts. A reduction in leadtime would imply a reduction in inventory and a reduction in costs. 


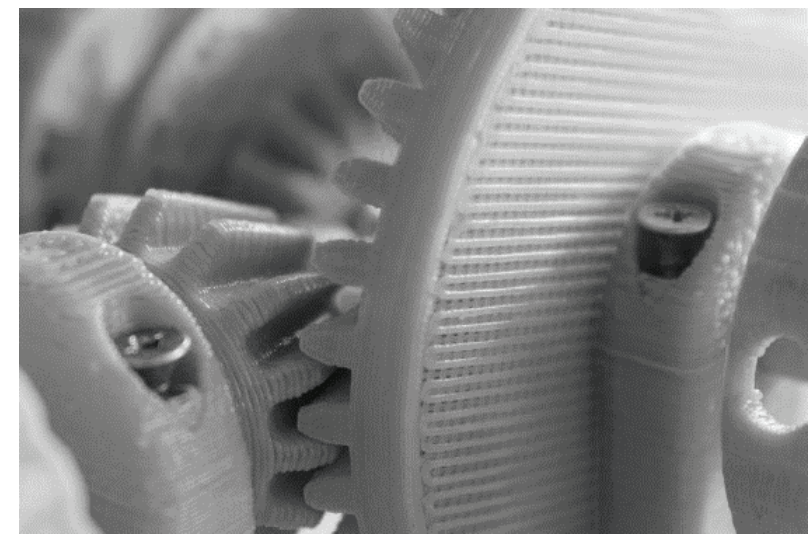

Fig. 3. Even basic 3D printers can be reprogrammed to create new designs at near zero marginal cost. Source: [13]

\section{Conclusion}

3D printing started, mainly as a means to create prototypes. The recent technological advancements and applications of 3D printing suggest that the technology has potential to revolutionize many facets of everyday life. The impact of AM on supply chains takes many forms, including simplified production processes, reduced material waste for leaner manufacturing, increased flexibility, reduced costs, faster reactions to demand, and the ability to decentralize production.

$3 \mathrm{D}$ printing opens up new opportunities and is slowly emerging as a valuable way to improve supply chain efficiencies. AM has the potential to reduce costs and increase profits. As a result, supply chain can quickly react to changes in the marketplace. It opens up new opportunities and provides many possibilities for companies looking to improve manufacturing efficiency. AM significantly streamlines traditional methods and has the potential to become the norm over decades to come. The technology provides freedom of design using standard CAD software, and it is not limited to manufacturing technology. It also enables cost effective product customization.

The technology has improved processes in many industries, including aerospace, automotive, industrial products, consumer products, defence, architecture, or healthcare. Experts believe that this technology will keep growing at a fast pace and play a major role in the future of supply chains.

However before that, 3D print technology has to overcome one big obstacle. To provide more information among people about all its abilities and innovations, there are still views the $3 \mathrm{D}$ printing from the time of its beginnings more than 5 years ago. Today the situation is different, and the claim that $3 \mathrm{D}$ printing increases the consumption of raw materials is misleading. The opposite is true. 3D printing will greatly impact waste logistics. But positively. A well-designed production process using $3 \mathrm{D}$ printing results in significant savings in consumed material and the amount of waste generated. As production will be closer to the consumer, there will be less need for packaging and shipping materials than ever before. And less waste in production is then given by the very essence of the additive process. Another erroneous view of 3D printing is that its main potential is for products made of plastics and usually components to final products. That's not true. The main potential of the technology is the use of a wide range of materials, not just plastics. For instance Metal 3D Printing has the ability and big potential to produce intricate, streamlined components with physical properties that can sometimes exceed those of parts 
manufactured by traditional means. Consequently, the technology has the potential to completely shift the way that we fabricate critical components. With it, we can create lightweight objects with unique geometries capable of decreasing material waste and energy consumption.

In other words, there's a "knowledge gap" between the technology available and the people must close before $3 \mathrm{D}$ printing can be a common method of manufacturing product.

This paper is supported by the research project "From horse-drawn railway to intermodal transport" within Visegrad Fund.

\section{References}

1. What Is 3D Printing, 3dprinting.com, Available online: https://3dprinting.com/what-is3d-printing/ (2017)

2. T. Campbell, C. Williams, O. Ivanova, B. Garrett, Could 3D Printing Change the World? Technologies, Potential, and Implications of Additive Manufacturing (Washington, DC: Atlantic Council of United States, 2011)

3. H. Lipson, M. Kurman, Fabricated: The New World of 3D Printing (John Wiley \& Sons, Hoboken, USA, 2013)

4. B. Berman, Business Horizons 55, 155-162 (2012)

5. G.R. Janssen, I.J. Blankers, E.A. Moolenburgh, A.L. Posthumus, The Impact of 3-D Printing on Supply Chain Management (TNO: Innovation for Life, April 2014)

6. M. Gravier, 3D Printing: Customers Taking Charge of the Supply Chain (Industry Week, April 12. 2016)

7. H.J. Nyman, P. Sarlin, 47th Hawaii International Conference on System Science, 41904199 (Waikoloa, 2014)

8. A. Wieland, scrmresearch.org, Available online: https://scmresearch.files.wordpress .com/2014/12/3d_printing_supply_chain.png (2014)

9. C. Alexander, Five Ways 3D Printing Is Transforming the Supply Chain (Supply \& Demand Chain Executive Blog, 8 April 2015)

10. H. Paris, et al., CIRP Annals - Manufacturing Technology 65, 29-32 (2016)

11. R. Bogue, Assembly Automation 33, 307-311 (2013)

12. R. Crandall, Where Will Additive Manufacturing Take Us? (APICS, 26 June 2016)

13. A. Gramulewicz, Raw Intelligence: How 3d Printing Is Transforming Supply Chains. Circulate, Available online: http://circulatenews.org/2017/01/how-3d-printing-istransforming-supply-chains/ (2017) 